\title{
The influence of stunting on obesity in adulthood: results from the EPIPorto cohort
}

\author{
Ana Henriques ${ }^{1, *} \dagger$ Vânia Teixeira ${ }^{2} \uparrow$, Hugo FV Cardoso ${ }^{3,4}$ and Ana Azevedo 1,3 \\ 'ISPUP-EPIUnit, Universidade do Porto, Rua das Taipas $n^{\circ} 135$, Porto 4050-600, Portugal: ${ }^{2}$ Unidade de Cuidados \\ Continuados, Hospital Escola - Fundação Fernando Pessoa, Gondomar, Portugal: ${ }^{3}$ Departamento de Ciências da \\ Saúde Pública e Forenses e Educação Médica, Faculdade de Medicina, Universidade do Porto, Porto, Portugal: \\ ${ }^{4}$ Department of Archaeology, Simon Fraser University, Burnaby, British Columbia, Canada
}

Submitted 11 August 2017: Final revision received 27 December 2017: Accepted 5 February 2018: First published online 15 March 2018

\begin{abstract}
Objective: To retrospectively investigate the association between short stature and increased sitting height ratio (SHR) - indicators of stunting - and obesity markers in adults.

Design: Cross-sectional evaluation of the EPIPorto cohort. Weight, height, sitting height and waist circumference were measured. Obesity was assessed for men and women through BMI and waist-to-height ratio (WHtR). Short stature (women, $<152 \mathrm{~cm}$; men, $<164 \mathrm{~cm}$ ) and high SHR (women, $\geq 54.05 \%$; men, $\geq 53.25 \%$ ) were taken as stunting measures. OR with $95 \%$ CI were computed using logistic regression models.

Setting: Representative sample of adults from EPIPorto, an adult cohort study from Porto, Portugal.

Subjects: A sample of 1682 adults, aged 18-86 years, was analysed.

Results: Higher obesity prevalence was found among women (BMI $\geq 30 \cdot 0 \mathrm{~kg} / \mathrm{m}^{2}$ : $25.5 v .13 \cdot 3 \%, P<0.001)$ and a higher proportion of men presented abdominal obesity (WHtR $\geq 0 \cdot 5: 80 \cdot 1 v \cdot 71 \cdot 1 \%, P<0 \cdot 001$ ). A positive association was found between short stature and obesity measures for women (multivariate-adjusted OR; $95 \%$ CI: $1.75 ; 1.17,2.62$ for $\mathrm{BMI} \geq 30.0 \mathrm{~kg} / \mathrm{m}^{2} ; 1.89 ; 1.24,2.87$ for WHtR $\geq 0.5$ ). Increased SHR was associated with higher likelihood of having BMI $\geq 30 \cdot 0 \mathrm{~kg} / \mathrm{m}^{2}$ in both sexes (multivariate-adjusted OR; 95\% CI: 2.10; 1.40, $3 \cdot 16$ for women; 1.92 ; $1 \cdot 07,3.43$ for men) but not with WHtR $\geq 0 \cdot 5$.

Conclusions: Different growth markers are associated with obesity in adults. However, this association depends on the population and anthropometric measures used: short stature is associated with a higher risk of presenting excessive weight in women but not in men; SHR is more sensitive to detect this effect in both sexes.
\end{abstract}

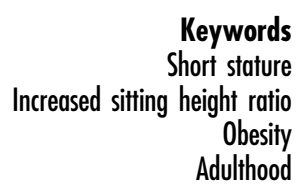

Longitudinal studies have shown that poor growth during the fetal, infant and childhood periods is associated with increased risk of obesity and related chronic diseases in adulthood $^{(1,2)}$. Additionally, prospective studies of adult cohorts have shown that leg length, as a marker of childhood growth, is inversely associated with the risk of obesity $^{(3,4)}, \mathrm{CVD}^{(5-7)}$ and the metabolic syndrome ${ }^{(8-10)}$. The use of the leg length as a marker of poor growth status is related to the cephalo-caudal growth gradient, the pattern of growth common to all mammals. A special feature of human growth is that between birth and puberty the legs grow relatively faster than other post-cranial body segments. Because legs grow faster than the trunk, their

$\dagger$ Both authors contributed equally as first authors to this paper. growth is also more susceptible to environmental stress during the postnatal period. Short stature due to relatively short legs is generally a marker of an adverse environment during infancy and childhood ${ }^{(11)}$.

Although height and leg length are associated with risk of chronic diseases, the sitting height ratio (SHR) allows individuals with different heights to be compared in terms of the percentage of the body that is composed by the relative length of the legs. Because the SHR is a better descriptor of body shape and body shape changes due to environmental stress than just height or leg length ${ }^{(12)}$, it is likely to show a stronger association with obesity and other risk factors. The SHR expresses the percentage of total stature that is due to the length of the head, neck and trunk $^{(13)}$. As a marker of early growth, the SHR of adults is, 
in part, indicative of net nutritional status, as it results from the synergetic relationship between nutrition, infection and physical activity during the most susceptible period of growth when the legs are growing faster ${ }^{(10,14)}$.

Several anthropometric measures have been used as proxies for total or abdominal fat to assess risk for several chronic diseases, the most widely recognized of which is $\mathrm{BMI}^{(15)}$. One of the measures proposed for abdominal obesity is waist-to-height ratio (WHtR), correcting the waist circumference (WC) for the height of the individual, and it is also correlated with abdominal fat measured using imaging techniques ${ }^{(16)}$. Additionally, the correction of WC for height offers the advantage that it is possible that a single WHtR boundary value may be useful in different ethnic, age and sex groups ${ }^{(17)}$.

An integrative approach to the effects of poor growth on adiposity has been lacking. Human growth is a complex influence of genomic, epigenetic, endocrine, environmental and socio-economic factors; therefore, as much as possible, it is important to bring together and tease out the multitude of possible factors affecting growth that can impact the risk of obesity later in life. Our aim was to investigate, retrospectively in a population-based cohort, the association between stunting as measured by short stature and relatively short legs (a high SHR) and adiposity in adults.

\section{Methods}

\section{Study design and participants}

The current research is based on the EPIPorto cohort study, comprised of 2485 Portuguese adults residing permanently in the city of Porto, Portugal, described in detail elsewhere $^{(18)}$. Participants were recruited between 1999 and 2003 by random digit dialling using households as the sampling frame, followed by simple random sampling to select one eligible person among permanent residents in each household. After being selected and informed about the study details, each participant was invited to visit our department to complete a demographic, social, behavioural and medical questionnaire, as well as an anthropometric assessment. The proportion of participation was $70 \%{ }^{(18)}$. Between 2005 and 2008, a follow-up study was conducted which included a face-to-face interview and a second anthropometric assessment. Since sitting height data were collected only during the follow-up study, the current analysis is based only on participants who attended both evaluations. At the follow-up examination, $68 \%$ of the cohort was re-evaluated, which results in a total of 1682 participants for the present analysis. In comparison to the remaining participants in the baseline assessment, our sample is younger and slightly more educated, but no differences were found in any of the anthropometric variables. Except for sitting height, all other variables were collected from the baseline evaluation.

\section{Data collection and definition of variables}

Age was recorded as a continuous variable. Education was recorded as completed years of schooling and later categorized into three groups: $\leq 4$ years, $5-11$ years or $\geq 12$ years of school enrolment. Occupation was categorized as non-manual, manual or not having a paid occupation (housewives or unemployed). Participants were classified as non-smokers (never smokers), current smokers (daily or occasional) or former smokers (for at least 6 months). Regarding total physical activity, the EPIPorto Physical Activity Questionnaire, a questionnaire exploring all professional, domestic and leisure-time activities, detailing the duration and intensity for each activity during the year prior to the interview, was used, described in detail elsewhere $^{(19)}$. This questionnaire was developed using a similar structure to the questionnaire in the European Prospective Investigation into Cancer and Nutrition (EPIC) and previous research showed that this questionnaire is a valid and reproducible instrument for the brief assessment of usual energy expenditure in Portuguese adults ${ }^{(20)}$. To calculate energy expenditure in physical activity, participants reported the average time spent per day or week in several activities (rest, transport, work, household activities, leisure-time exercise) and energy expenditure was estimated by multiplying the related metabolic equivalent of task (MET) values by the time spent in each activity (MET-h/d). Total energy intake was estimated based on a validated semi-quantitative FFQ of the previous 12 months, comprising eighty-two food items or beverage categories, described in detail elsewhere ${ }^{(21)}$.

Anthropometric measurements included body weight, height, sitting height, WC, BMI and WHtR. All measurements were collected with participants wearing light clothing and no footwear. Body weight was measured to the nearest $0.1 \mathrm{~kg}$ using a digital scale and height was measured to the nearest centimetre in the standing position using a wall stadiometer. Sitting height was measured with the participant sitting upright on a base plate, using the same stadiometer, and later subtracting the plate's height. WC was measured to the nearest centimetre with a flexible and non-stretchable tape, avoiding exertion of pressure on the tissues and with the participant standing. The measure was performed midway between the lower limit of the rib cage and the iliac crest. BMI was calculated as weight (in kilograms) divided by the square of height (in metres), and further divided into the categories proposed by the $\mathrm{WHO}^{(22)}$. WC and height measures were used to calculate participants' WHtR, defined as WC divided by height, both measured in centimetres. Abdominal obesity was defined as WHtR $\geq 0.5$ for men and women $^{(23)}$.

Height below the first quartile of the sample distribution $(<152 \mathrm{~cm}$ in women and $<164 \mathrm{~cm}$ in men) was considered low and interpreted as short stature. Participants' SHR was used as a measure of relative leg length and was calculated using the formula: $\operatorname{SHR}=($ sitting height $/$ height $) \times 100$. 
The lower the SHR, the relatively longer the legs are ${ }^{(13)}$. A SHR above the third quartile of the sample distribution ( $\geq 54.05 \%$ in women and $\geq 53.25 \%$ in men) was considered high, implying these individuals had relatively short legs for their height.

\section{Statistical analysis}

Sample characteristics are presented as counts and proportions for categorical variables, mean and standard deviation for continuous variables with approximately symmetrical distributions, and median and interquartile range for continuous variables with markedly skewed distributions. We compared several sociodemographic characteristics using the $\chi^{2}$ test for categorical variables and the independent-samples Student $t$ test for continuous variables.

Height and SHR were taken as exposures (independent variables) and their association with BMI and WHtR (dependent variables) was assessed. For an initial examination of the effects of height and SHR on obesity, both variables were considered as continuous and later categorized by quartiles to formally test the existence of a linear association between exposures and outcomes (data not shown). Since distinct associations were found for specific quartiles, both for height and SHR, these analyses supported a dichotomization for height below the first quartile and for SHR above the third quartile. The association between the exposures and measures of adiposity was then quantified using logistic regression models and the results are presented as crude, age-adjusted and multivariate-adjusted odds ratios with $95 \%$ confidence intervals. Each final model was fitted to quantify the association of stature and SHR (independent variable or exposure) with BMI and WHtR (dependent variable or outcome), adjusting for confounders, taking account of the literature review. In order to identify the confounders of the main associations, besides a significance level that was set at a level of $0 \cdot 05$, backward elimination and change in estimation methods were used ${ }^{(24)}$ : variables that did not cause changes of more than $10 \%$ in the exposure effect estimate upon deletion (compared with the full model estimate) were removed. Within the same outcome, the Bayesian information criterion (BIC) was used to compare the fit across models, one using stature and the other using SHR as the main exposures. All analyses were stratified by sex, due to the known pathophysiological differences in adiposity.

Statistical analyses were performed using the statistical software package Stata version 11.0 and the significance level was fixed at $P<0.05$.

\section{Results}

A description of the study sample by the various variables is shown in Table 1. At baseline, mean age was $52 \cdot 0$ (SD 14.0) years for women and 52.8 (SD 14.9) years for men. Forty-one per cent of the women and $30 \%$ of the men had four or less years of education. More than half of the individuals had non-manual occupations $(53.3$ and $65.8 \%$ of women and men, respectively). A higher percentage of men were current or former smokers at baseline $(70 \cdot 8 \%, v .27 .5 \%$ of women). Similar levels of total physical activity were found in both sexes; however, the mean total energy intake was lower among women than men $(8648 \mathrm{~kJ} / \mathrm{d}(2067 \mathrm{kcal} / \mathrm{d}) v$. $10615 \mathrm{~kJ} / \mathrm{d}(2537 \mathrm{kcal}), P<0 \cdot 001)$. Mean height and SHR were 155.9 (sD 6.0 ) $\mathrm{cm}$ and 53.1 (SD 1.6) \% for women, and 169.0 (SD 6.9) $\mathrm{cm}$ and 52.3 (sD 1.5) \% for men, respectively. A higher prevalence of obesity was found among women than men $(25.5 v .13 .3 \%)$, yet men were more frequently overweight (49.2 $v \cdot 36 \cdot 2 \%)$. For WHtR, a higher proportion of men presented abdominal obesity defined as $\mathrm{WH} \mathrm{HR} \geq 0.5$ (80.1 v. 71.1\%; Table 1).

Table 2 presents the association of height and sitting height with BMI and WHtR, by sex. For height, a gradual and positive association was found between short height and excessive weight among women (obesity: multivariateadjusted $\mathrm{OR}=1 \cdot 75,95 \% \mathrm{CI} 1 \cdot 17,2 \cdot 62$ ) but not among men (obesity: multivariate-adjusted $\mathrm{OR}=0.74,95 \% \mathrm{CI} 0 \cdot 40,1 \cdot 39$ ), independently of age, education and smoking status. Likewise, sex differences were found for the association between short stature and WHtR: women with short height showed almost a twofold increase in the odds of abdominal obesity (multivariate-adjusted $\mathrm{OR}=1 \cdot 89,95 \%$ CI 1.24, 2.87) while no association was found among men (multivariateadjusted $\mathrm{OR}=1 \cdot 15,95 \% \mathrm{CI} 0 \cdot 66,2 \cdot 02$ ).

For the relationship between SHR and obesity, results were similar for women and men. After adjustment for confounders, having relatively short legs (a high SHR) was associated with a higher likelihood of being overweight (women: multivariate-adjusted $\mathrm{OR}=1 \cdot 56,95 \% \mathrm{CI} 1 \cdot 08,2 \cdot 26$; men: multivariate-adjusted $\mathrm{OR}=1 \cdot 69,95 \% \mathrm{CI} 1 \cdot 10,2 \cdot 59$ ) and obese (women: multivariate-adjusted $\mathrm{OR}=2 \cdot 10,95 \% \mathrm{CI}$ 1.40, 3.16; men: multivariate-adjusted $\mathrm{OR}=1 \cdot 92,95 \% \mathrm{CI}$ $1.07,3.43)$. Men and women showed weaker associations between SHR and WHtR (women: multivariate-adjusted $\mathrm{OR}=1 \cdot 28,95 \% \mathrm{CI}$ 0.90, 1.83; men: multivariate-adjusted $\mathrm{OR}=1 \cdot 55,95 \%$ CI 0.92, 2.59; Table 2).

Taking account of BMI, a model including SHR as an indicator of stunting showed better fit than the model using stature, for both sexes (women: $\mathrm{BIC}=2011 \cdot 17 v$. 2048.86; men: $\mathrm{BIC}=1245.52 v \cdot 1264 \cdot 32$ ). Regarding WHtR, a model with height was the best-fitting for women, presenting the smallest BIC (995.81 v. 1011.87), while for men a model with SHR instead of stature had better fit (BIC $=581.88 v .583 .66)$.

\section{Discussion}

The present study shows that stunted height and stunted leg length are associated with the development of obesity 
Table 1 Characteristics of the study sample, by sex: adults aged 18-86 years ( $n$ 1682) from the EPIPorto adult cohort study, Porto, Portugal (baseline 1999-2003, follow-up 2005-2008)

\begin{tabular}{|c|c|c|c|c|c|}
\hline & \multicolumn{2}{|c|}{ Women } & \multicolumn{2}{|c|}{ Men } & \multirow[b]{2}{*}{$P$} \\
\hline & $n$ or Mean & $\%$ or SD & $n$ or Mean & $\%$ or SD & \\
\hline Overall & 1048 & $62 \cdot 3$ & 634 & $37 \cdot 7$ & \\
\hline Age at baseline (years) & $52 \cdot 0$ & $14 \cdot 0$ & $52 \cdot 8$ & 14.9 & 0.285 \\
\hline \multicolumn{6}{|l|}{ Education (years) } \\
\hline$\leq 4$ & 428 & $40 \cdot 8$ & 189 & $30 \cdot 0$ & \\
\hline$\overline{5}-11$ & 272 & $26 \cdot 0$ & 220 & 34.9 & \\
\hline$\geq 12$ & 348 & $33 \cdot 2$ & 222 & 39.0 & $<0.001$ \\
\hline \multicolumn{6}{|l|}{ Occupation } \\
\hline Non-manual & 558 & $53 \cdot 3$ & 416 & $65 \cdot 8$ & \\
\hline Manual & 346 & 33.0 & 199 & 31.5 & \\
\hline No paid occupation & 144 & $13 \cdot 7$ & 17 & $2 \cdot 7$ & $<0.001$ \\
\hline \multicolumn{6}{|l|}{ Smoking status } \\
\hline Never & 746 & $72 \cdot 5$ & 183 & $29 \cdot 3$ & \\
\hline Current & 172 & $16 \cdot 7$ & 211 & $33 \cdot 8$ & \\
\hline Former & 111 & $10 \cdot 8$ & 231 & $37 \cdot 0$ & $<0.001$ \\
\hline \multicolumn{6}{|c|}{ Total physical activity (MET-h/d) } \\
\hline Median & \multirow{2}{*}{\multicolumn{2}{|c|}{$\begin{array}{c}34 \cdot 7 \\
33 \cdot 2-38 \cdot 4\end{array}$}} & \multirow{2}{*}{\multicolumn{2}{|c|}{$\begin{array}{c}34 \cdot 3 \\
32 \cdot 7-39 \cdot 6\end{array}$}} & 0.363 \\
\hline IQR & & & & & \\
\hline Total energy intake (kJ/d) & 8648 & 2351 & 10615 & 2703 & $<0.001$ \\
\hline Total energy intake $(\mathrm{kcal} / \mathrm{d})$ & 2067 & 562 & 2537 & 646 & $<0.001$ \\
\hline Height $(\mathrm{cm})$ & $155 \cdot 9$ & $6 \cdot 0$ & $169 \cdot 0$ & 6.9 & $<0.001$ \\
\hline SHR (\%) & 53.1 & 1.6 & $52 \cdot 3$ & 1.5 & $<0.001$ \\
\hline \multicolumn{6}{|l|}{$\mathrm{BMI}\left(\mathrm{kg} / \mathrm{m}^{2}\right)$} \\
\hline$<25.0$ & 396 & $38 \cdot 3$ & 235 & 37.5 & \\
\hline $25 \cdot 0-29 \cdot 9$ & 374 & $36 \cdot 2$ & 308 & $49 \cdot 2$ & \\
\hline$\geq 30.0$ & 263 & $25 \cdot 5$ & 83 & $13 \cdot 3$ & $<0.001$ \\
\hline \multicolumn{6}{|l|}{ WHtR } \\
\hline$<0.5$ & 303 & 28.9 & 126 & $19 \cdot 9$ & \\
\hline$\geq 0.5$ & 745 & $71 \cdot 1$ & 508 & $80 \cdot 1$ & $<0.001$ \\
\hline
\end{tabular}

MET, metabolic equivalent of task; IQR, interquartile range; SHR, sitting height ratio; WHtR, waist-to-height ratio.

Data presented are $n$ and \% for categorial variables, mean and SD for approximately symmetrical distributions, or median and IQR for continuous variables with markedly skewed distributions. For each variable, the total may not add up to 1682 due to missing data.

Table 2 Crude and adjusted odds ratios for the association of short stature and relative short leg length (i.e. a high SHR) with overweight/ obesity and abdominal obesity, by sex, among adults aged 18-86 years ( $n$ 1682) from the EPIPorto adult cohort study, Porto, Portugal (baseline 1999-2003, follow-up 2005-2008)

\begin{tabular}{|c|c|c|c|c|c|c|c|c|c|c|c|c|c|}
\hline & \multicolumn{6}{|c|}{ Women } & \multicolumn{6}{|c|}{ Men } & \multirow{3}{*}{$\begin{array}{c}P \text { for the } \\
\text { interaction } \\
\text { with sex }\end{array}$} \\
\hline & \multicolumn{2}{|r|}{ Crude } & \multicolumn{2}{|c|}{ Age-adjusted } & \multicolumn{2}{|c|}{$\begin{array}{l}\text { Multivariate- } \\
\text { adjusted }^{*}\end{array}$} & \multicolumn{2}{|r|}{ Crude } & \multicolumn{2}{|c|}{ Age-adjusted } & \multicolumn{2}{|c|}{$\begin{array}{l}\text { Multivariate- } \\
\text { adjusted }^{\star}\end{array}$} & \\
\hline & OR & $95 \% \mathrm{Cl}$ & OR & $95 \% \mathrm{Cl}$ & OR & $95 \% \mathrm{Cl}$ & OR & $95 \% \mathrm{Cl}$ & OR & $95 \% \mathrm{Cl}$ & OR & $95 \% \mathrm{Cl}$ & \\
\hline \multicolumn{14}{|c|}{$\begin{array}{l}\text { Dependent variables } \\
\text { BMI }\left(\mathrm{kg} / \mathrm{m}^{2}\right)\end{array}$} \\
\hline $\begin{array}{l}\quad<25.0 \\
25.0-29.9 \\
\geq 30.0 \\
\text { WHtR }\end{array}$ & $\begin{array}{l}1.00 \\
2.56 \\
3.07\end{array}$ & $\begin{array}{c}\text { Ref. } \\
1.82,3.60 \\
2.13,4.43\end{array}$ & $\begin{array}{l}1.00 \\
1.85 \\
2 \cdot 17\end{array}$ & $\begin{array}{c}\text { Ref. } \\
1.29,2.65 \\
1.48,3.18\end{array}$ & $\begin{array}{l}1.00 \\
1.60 \\
1.75\end{array}$ & $\begin{array}{c}\text { Ref. } \\
1 \cdot 10,2 \cdot 32 \\
1 \cdot 17,2 \cdot 62\end{array}$ & $\begin{array}{l}1.00 \\
0.96 \\
0.86\end{array}$ & $\begin{array}{c}\text { Ref. } \\
0.64,1.41 \\
0.48,1.56\end{array}$ & $\begin{array}{l}1.00 \\
0.80 \\
0.77\end{array}$ & $\begin{array}{c}\text { Ref. } \\
0.54,1.20 \\
0.42,1.41\end{array}$ & $\begin{array}{l}1.00 \\
0.86 \\
0.74\end{array}$ & $\begin{array}{c}\text { Ref. } \\
0.56,1.30 \\
0.40,1.39\end{array}$ & $\begin{array}{l}0.055 \\
0.002\end{array}$ \\
\hline $\begin{array}{l}<0.5 \\
\geq 0.5\end{array}$ & $\begin{array}{l}1.00 \\
3.50\end{array}$ & $\begin{array}{l}\text { Ref. } \\
2 \cdot 42,5.07\end{array}$ & $\begin{array}{l}1.00 \\
2 \cdot 27\end{array}$ & $\begin{array}{c}\text { Ref. } \\
1.51,3.40\end{array}$ & $\begin{array}{l}1.00 \\
1.89\end{array}$ & $\begin{array}{c}\text { Ref. } \\
1 \cdot 24,2 \cdot 87\end{array}$ & $\begin{array}{l}1.00 \\
1.70\end{array}$ & $\begin{array}{c}\text { Ref. } \\
1.03,2.80\end{array}$ & $\begin{array}{l}1.00 \\
1 \cdot 18\end{array}$ & $\begin{array}{c}\text { Ref. } \\
0.69,2.00\end{array}$ & $\begin{array}{l}1.00 \\
1.15\end{array}$ & $\begin{array}{c}\text { Ref. } \\
0.66,2.02\end{array}$ & 0.269 \\
\hline \multicolumn{14}{|c|}{$\begin{array}{l}\text { Independent variable: high SHR } \\
\text { Dependent variables }\end{array}$} \\
\hline $\begin{array}{l}<25.0 \\
25.0-29.9 \\
\geq 30.0\end{array}$ & $\begin{array}{l}1.00 \\
1.10 \\
1.49\end{array}$ & $\begin{array}{c}\text { Ref. } \\
0.79,1.54 \\
1.04,2.13\end{array}$ & $\begin{array}{l}1.00 \\
1.52 \\
2.13\end{array}$ & $\begin{array}{c}\text { Ref. } \\
1.06,2 \cdot 18 \\
1.45,3.14\end{array}$ & $\begin{array}{l}1.00 \\
1.56 \\
2 \cdot 10\end{array}$ & $\begin{array}{c}\text { Ref. } \\
1.08,2 \cdot 26 \\
1.40,3 \cdot 16\end{array}$ & $\begin{array}{l}1.00 \\
1.63 \\
1.94\end{array}$ & $\begin{array}{c}\text { Ref. } \\
1.08,2.46 \\
1.10,3.42\end{array}$ & $\begin{array}{l}1.00 \\
1.77 \\
2.05\end{array}$ & $\begin{array}{c}\text { Ref. } \\
1 \cdot 16,2 \cdot 69 \\
1 \cdot 16,3 \cdot 63\end{array}$ & $\begin{array}{l}1.00 \\
1.69 \\
1.92\end{array}$ & $\begin{array}{c}\text { Ref. } \\
1 \cdot 10,2.59 \\
1.07,3.43\end{array}$ & $\begin{array}{l}0.119 \\
0.534\end{array}$ \\
\hline WHtR & 19u & 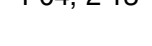 & 2.10 & דורט, דרו & 2. & טרום , דרו & דטי1 & 1. & 200 & שרט & re & טדרט, וטרו & דיט \\
\hline $\begin{array}{l}<0.5 \\
\geq 0.5\end{array}$ & $\begin{array}{l}1.00 \\
0.92\end{array}$ & $\begin{array}{l}\text { Ref. } \\
0.68,1.25\end{array}$ & $\begin{array}{l}1.00 \\
1.32\end{array}$ & $\begin{array}{c}\text { Ref. } \\
0.93,1.87\end{array}$ & $\begin{array}{l}1.00 \\
1.28\end{array}$ & $\begin{array}{l}\text { Ref. } \\
0.90,1.83\end{array}$ & $\begin{array}{l}1.00 \\
1.44\end{array}$ & $\begin{array}{l}\text { Ref. } \\
0.89,2.33\end{array}$ & $\begin{array}{l}1.00 \\
1.67\end{array}$ & $\begin{array}{c}\text { Ref. } \\
1 \cdot 01,2 \cdot 77\end{array}$ & $\begin{array}{l}1.00 \\
1.55\end{array}$ & $\begin{array}{c}\text { Ref. } \\
0.92,2.59\end{array}$ & 0.576 \\
\hline
\end{tabular}

WHtR, waist-to-height ratio; SHR, sitting height ratio; Ref., reference category.

${ }^{*}$ Adjusted for age (continuous), education (4, 5-11, $\geq 12$ years) and smoking (never, current, former).

†Short stature: $<152 \mathrm{~cm}$ (women); $<164 \mathrm{~cm}$ (men).

łHigh SHR: $\geq 54.05 \%$ (women); $\geq 53.25 \%$ (men). 
during adulthood, particularly in women. Shorter women are more likely to be overweight and obese than their taller counterparts, independently of their age, education and smoking status. A similar effect was not observed in men. The SHR appears to be a more sensitive anthropometric measure to identify obesity in both sexes, as both men and women with relatively shorter legs had a higher risk of being overweight or obese. While women showed a similar effect for WHtR, this was not the case for men.

First, regarding height, our results are in accordance with previous cross-sectional studies showing that short adult stature, a marker of early and chronic undernutrition, is a risk factor for obesity among women, but not among men ${ }^{(25-27)}$. One possible explanation might be the low energy expenditure among women exposed to energy restriction during development, as shown in adolescent girls with stunting ${ }^{(28)}$. However, another study conducted in Brazil found a stronger association between short stature and obesity prevalence for both sexes, although stronger in women ${ }^{(29)}$. Some methodological issues, such as self-reported BMI and use of the 5th percentile of the height distribution as the cut-off for early undernutrition, might explain the differences found between that study and our results. Another interesting finding in the Brazilian study is that the association with BMI at the age of 20 years was three times stronger than the association found with $\mathrm{BMI}$ at the time of the evaluation, suggesting that BMI is strongly influenced by an individual's early nutrition but loses magnitude as time goes by due to other factors contributing to weight gain throughout adulthood. In our sample, the mean age at baseline was 52 years and it was not possible to have anthropometric data at earlier ages; therefore, future studies should conduct similar analyses using younger samples and evaluate them longitudinally. These studies will examine whether there is any association between short stature and obesity among men in early adulthood and also verify in which period of the life cycle the association is stronger, thus providing information about the best time to act preventively in this population. Another potential explanation for a differing association between height and BMI in men and women is related to body composition. BMI is a crude measure of adiposity, as women have more fat mass relative to weight than men, who have more lean mass for the same weight. Because of more adiposity for weight in women, the association with height might reflect the influence of poor growth on the risk of adiposity in women (who have more fat mass) compared with men (who have more lean mass).

Use of the SHR provided a more sensitive approach to examining how poor growth is reflected in an increased risk of obesity. This measure seems to be more responsive possibly because it is a measure of leg length that controls for differences in height ${ }^{(30)}$. In our study, SHR was revealed to be a more sensitive measure to identify men and women with higher risk of excessive weight. The inverse relationship between measures of relative leg length and adiposity was previously reported by other authors in different populations ${ }^{(4,31)}$. Particularly in the USA, a significant relationship between BMI and SHR was found for men and women of three major ethnic-social groups, namely Whites, Blacks and Mexican Americans: adults with relatively longer legs for their total height had lower $\mathrm{BMI}^{(32)}$.

The 'sitting height' component of the SHR measures the length of the head, neck, chest and abdomen. Accordingly, if all other aspects of body composition were equal, then for two people of equal sitting height, the BMI will be greater in the person with relatively shorter legs. According to Bogin and Beydoun ${ }^{(32)}$, this fundamental biometric relationship is not enough to account for these findings. A possible explanation for this relationship comes from research in human life history and the tradeoffs that occur between early development and later growth and health outcomes. Poor nutrition and health during pregnancy and during the first six years of life postpartum result in fetuses, newborns, infants and children of reduced body length, mostly due to reduced leg length ${ }^{(33,34)}$. The alterations in body proportions are likely due to competition between body segments, such as trunk $v$. limbs, and organs for the limited nutrients ${ }^{(12)}$.

It is hypothesized that SHR is a more sensitive factor to environmental effects than stature and that differences in relative leg/trunk proportions between individuals result from growth being affected at different periods with different intensities ${ }^{(14)}$. Because leg length during childhood and adolescence increases very rapidly and contributes more to the variability in stature, it is more sensitive to environmental exposures than the slower growing trunk size ${ }^{(31)}$. This reinforces the idea that stature and SHR convey different information. The SHR controls for differences in overall size between individuals and, therefore, is likely to show a stronger association with obesity and chronic diseases than stature ${ }^{(14)}$, as was observed in the current study.

Concerning the measures that we used to assess adiposity, we are aware that there are various ways to measure different aspects of obesity and all of them have strengths and limitations. The rationale for using BMI instead of weight to define obesity is that, if body composition is proportionally the same, taller people weigh more ${ }^{(35)}$. Thus, modelling weight as a function of height is expected to show an inverse association which says nothing about adiposity. The same rationale applies to WC: for perfect proportionality, taller people (i.e. larger people) will have larger WC. Moreover, the use of BMI and WHtR is supported by literature that confirms that the mere presence of ratios with a common denominator on both sides of a regression equation does not make the results from the model spurious ${ }^{(36)}$. Also, BMI is commonly used as a surrogate measure of fatness ${ }^{(37)}$, it is one of the most accurate surrogate markers of visceral fat and is a good indicator of insulin resistance ${ }^{(38)}$. Moreover, its associations with 
mortality and several co-morbidities are well established ${ }^{(39-41)}$ and their clinical meaning validated ${ }^{(22)}$. Regarding WHtR, this measure is significantly associated with all the risk factors for obesity and metabolic syndrome and can predict morbidity and mortality in longitudinal studies better than BMI ${ }^{(30,42)}$. Furthermore, the use of WHtR can often identify people within a moderate range of BMI who have a higher metabolic risk ${ }^{(43)}$ and can be even more sensitive than WC in several different populations possibly because it encompasses the adjustment to different statures $^{(17)}$. Both these indices are cost-effective, easy to measure, have the same cut-offs in men and women, and allow us to provide a simple public health message to the population. For all these reasons, we believe that BMI and WHtR are important primary screening tools to assess adiposity and they should be considered in research and clinical practice.

For each one of the main associations studied, other confounders were tested based on previous knowledge, such as occupation, leisure-time physical activity, energy intake and reproductive state (for women), but no significant associations were found. Since socio-economic position early in life is also related to adult $\mathrm{BMI}^{(44)}$, the impact of the parents' socio-economic position (as measured by manual $v$. non-manual occupations) was also assessed, but no associations were found in either males or females (data not shown). One of the limitations concerning this variable is that we only analysed parental occupation; and parental education, known to be an indicator of the quality of growth environment reflecting the quality of health care and nutrition ${ }^{(45)}$, was not assessed in our study.

To better interpret the results of the present study, some methodological issues need to be considered. More than half of the individuals had non-manual occupations and more than a third had a higher level of education, suggesting that the study population might be biased towards a high socioeconomic position. Since we only analysed individuals who also participated in the follow-up evaluation and individuals with higher socio-economic position are more likely to participate in follow-up evaluations ${ }^{(46,47)}$, we might have experienced a selection bias. However, we evaluated almost $70 \%$ of the total cohort and therefore believe that the possible selection bias is not sufficient to change the direction of the associations found. Also, the SHR can be overestimated in individuals with high levels of gluteofemoral fat, which contributes to a higher sitting height, therefore underestimating the relative contribution of the lower limb to total stature $^{(13)}$. Since obese people have more gluteofemoral fat, this would result in an underestimation of the association between SHR and adiposity due to a differential information bias. This should not, however, fully explain the results found, since they are in accordance with previous literature.

Our results may reflect differences in nutrition that might have existed in Portugal during the 1960s and 1970s. In contrast to many other European countries, patterns of growth and development in Portugal remained relatively unchanged for most of the 20th century since the country experienced a period of economic stagnation and a long dictatorship ${ }^{(48)}$. Since the 1970 s changes in social, health and sanitary conditions resulted in a positive increment in height of Portuguese citizens ${ }^{(49)}$. The mean age of this sample is 52 years, which means that half of the individuals were born and grew before the 1970s. Thus, the EPIPorto sample represents a population with a wide variation in ages in transition and includes individuals who were exposed to a relatively deprived and difficult period and others exposed to a more positive environment. Further research should study these same associations in younger populations, with a lower range of ages, to examine whether the consequences of early deprivation remain the same for those born after the 1970s.

Growth deficits produced by negative environmental conditions during periods of growth and development have been extensively associated with health status, namely metabolic diseases ${ }^{(10,50,51)}$ and $\mathrm{CHD}^{(6,9,52)}$. This growing body of evidence, together with our research, highlights the importance of considering a life-course approach in health, particularly in obesity. Due to its strong association with several co-morbidities ${ }^{(41)}$, a deeper knowledge of how early-life experiences are linked with this epidemic will help prevent and predict not only obesity but several other related diseases. Moreover, it is also interesting to notice that the association of height and relative leg length with BMI and WHtR shows a strong effect in the crude models, and that this strength is lost when the effect of confounders is adjusted for. This suggests that lifestyle variables and individual life trajectory also play significant roles in adult adiposity and need to be taken into account when measuring the impact of poor growth on obesity during adulthood.

\section{Conclusion}

Having relatively short legs was found to be a risk factor for overweight/obesity in Portuguese adult women and men. Short stature appears to be associated with obesity and adiposity only in women. The SHR is more sensitive to assess the effect of stunting on obesity in adulthood than stature. Environmental, behavioural and genetic factors that affect the increase of SHR and the decrease of stature should be studied in depth to provide important clues for better weight control recommendations. From a clinical perspective, findings from the present study may help health professionals to identify earlier in life those patients with a higher risk of becoming obese in adulthood and, in turn, prevent a suite of CVD.

\section{Acknowledgements}

Financial support: This study was funded by the European Regional Development Fund (FEDER) through the 
Operational Programme Competitiveness and Internationalization; and by national funding from the Foundation for Science and Technology (FCT) (Portuguese Ministry of Science, Technology and Higher Education) under the Unidade de Investigação em Epidemiologia - Instituto de Saúde Pública da Universidade do Porto (EPIUnit) (grant number POCI-01-0145-FEDER-006862; ref. UID/DTP/ 04750/2013). The EPIPorto study was funded by the FCT (grant numbers PraxisXXI//2/2.1/SAU/1332/95 and POCTI/ $\mathrm{ESP} / 35769 / 99)$. The funders had no role in the design, analysis or writing of this article. Conflict of interest: There are no conflicts of interest to disclose. Authorship: Each author participated sufficiently in the work to take public responsibility for its content and believes that the manuscript represents honest work. A.H. and V.T. collaborated in the analysis and interpretation of the data and wrote the article. H.F.V.C. collaborated in the study design, data analysis and reviewed the article with important intellectual content. A.A. designed the study, analysed and interpreted the data and reviewed the article critically. Ethics of human subject participation: This study was conducted according to the guidelines laid down in the Declaration of Helsinki and all procedures involving human subjects were approved by the Ethics Committee of Hospital de São João. Written informed consent was obtained from all subjects.

\section{References}

1. Law CM, Shiell AW, Newsome CA et al. (2002) Fetal, infant, and childhood growth and adult blood pressure: a longitudinal study from birth to 22 years of age. Circulation $\mathbf{1 0 5}$, 1088-1092.

2. Schroeder DG, Martorell R \& Flores R (1999) Infant and child growth and fatness and fat distribution in Guatemalan adults. Am J Epidemiol 149, 177-185.

3. Smith PK, Bogin B, Varela-Silva MI et al. (2003) Economic and anthropological assessments of the health of children in Maya immigrant families in the US. Econ Hum Biol 1, $145-160$.

4. Velasquez-Melendez G, Silveira EA, Allencastro-Souza P et al. (2005) Relationship between sitting-height-to-stature ratio and adiposity in Brazilian women. Am J Hum Biol 17, 646-653.

5. Lawlor DA, Davey Smith G \& Ebrahim S (2003) Association between leg length and offspring birthweight: partial explanation for the trans-generational association between birthweight and cardiovascular disease: findings from the British Women's Heart and Health Study. Paediatr Perinat Epidemiol 17, 148-155.

6. Lawlor DA, Taylor M, Davey Smith G et al. (2004) Associations of components of adult height with coronary heart disease in postmenopausal women: the British Women's Heart and Health Study. Heart 90, 745-749.

7. Langenberg C, Hardy R, Kuh D et al. (2003) Influence of height, leg and trunk length on pulse pressure, systolic and diastolic blood pressure. J Hypertens 21, 537-543.

8. Bogin B \& Varela-Silva MI (2003) Anthropometric variation and health: a biocultural model of human growth. $J$ Child Health 1, 149-172.

9. Smith GD, Greenwood R, Gunnell D et al. (2001) Leg length, insulin resistance, and coronary heart disease risk: the Caerphilly study. J Epidemiol Community Health 55, $867-872$.
10. Varela-Silva MI, Frisancho AR, Bogin B et al. (2007) Behavioral, environmental, metabolic and intergenerational components of early life undernutrition leading to later obesity in developing nations and in minority groups in the USA. Coll Antropol 31, 39-46.

11. Wu YH, Moore S \& Dube L (2017) Social capital and obesity among adults: longitudinal findings from the Montreal neighborhood networks and healthy aging panel. Prev Med. Published online: 29 November 2017. doi:10.1016/j.ypmed. 2017.11.028.

12. Kawachi I \& Subramanian SV (2018) Social epidemiology for the 21st century. Soc Sci Med 196, 240-245.

13. Bogin B \& Varela-Silva MI (2008) Fatness biases the use of estimated leg length as an epidemiological marker for adults in the NHANES III sample. Int J Epidemiol 37, 201-209.

14. Bogin B \& Varela-Silva MI (2010) Leg length, body proportion, and health: a review with a note on beauty. Int $J$ Environ Res Public Health 7, 1047-1075.

15. Soto Gonzalez A, Bellido D, Buno MM et al. (2007) Predictors of the metabolic syndrome and correlation with computed axial tomography. Nutrition 23, 36-45.

16. Ashwell M, Cole TJ \& Dixon AK (1996) Ratio of waist circumference to height is strong predictor of intraabdominal fat. BMJ 313, 559-560.

17. Ashwell M \& Hsieh SD (2005) Six reasons why the waist-toheight ratio is a rapid and effective global indicator for health risks of obesity and how its use could simplify the international public health message on obesity. Int J Food Sci Nutr 56, 303-307.

18. Ramos E, Lopes C \& Barros H (2004) Investigating the effect of nonparticipation using a population-based case-control study on myocardial infarction. Ann Epidemiol 14, 437-441.

19. Camoes M \& Lopes C (2008) Dietary intake and different types of physical activity: full-day energy expenditure, occupational and leisure-time. Public Health Nutr 11, 841-848.

20. Camoes M, Severo M, Santos AC et al. (2010) Testing an adaptation of the EPIC physical activity questionnaire in Portuguese adults: a validation study that assesses the seasonal bias of self-report. Ann Hum Biol 37, 185-197.

21. Lopes C, Aro A, Azevedo A et al. (2007) Intake and adipose tissue composition of fatty acids and risk of myocardial infarction in a male Portuguese community sample. $J \mathrm{Am}$ Diet Assoc 107, 276-286.

22. World Health Organization (1998) Clinical guidelines on the identification, evaluation, and treatment of overweight and obesity in adults: executive summary. Expert panel on the identification, evaluation, and treatment of overweight in adults. Am J Clin Nutr 68, 899-917.

23. Browning LM, Hsieh SD \& Ashwell M (2010) A systematic review of waist-to-height ratio as a screening tool for the prediction of cardiovascular disease and diabetes: 0.5 could be a suitable global boundary value. Nutr Res Rev $\mathbf{2 3}$, 247-269.

24. Budtz-Jorgensen E, Keiding N, Grandjean P et al. (2007) Confounder selection in environmental epidemiology: assessment of health effects of prenatal mercury exposure. Ann Epidemiol 17, 27-35.

25. Bosy-Westphal A, Plachta-Danielzik S, Dorhofer RP et al. (2009) Short stature and obesity: positive association in adults but inverse association in children and adolescents. Br J Nutr 102, 453-461.

26. Castano LS, Restrepo AE, Rueda JD et al. (2013) The effects of socioeconomic status and short stature on overweight, obesity and the risk of metabolic complications in adults. Colomb Med (Cali) 44, 146-154.

27. Velasquez-Melendez G, Martins IS, Cervato AM et al. (1999) Relationship between stature, overweight and central obesity in the adult population in Sao Paulo, Brazil. Int $J$ Obes Relat Metab Disord 23, 639-644. 
28. Grillol LP, Siqueira AF, Silva AC et al. (2005) Lower resting metabolic rate and higher velocity of weight gain in a prospective study of stunted vs nonstunted girls living in the shantytowns of Sao Paulo, Brazil. Eur J Clin Nutr 59, 835-842.

29. Sichieri R, Dos Santos Barbosa F \& Moura EC (2010) Relationship between short stature and obesity in Brazil: a multilevel analysis. Br J Nutr 103, 1534-1538.

30. Patel S, Unwin N, Bhopal R et al. (1999) A comparison of proxy measures of abdominal obesity in Chinese, European and South Asian adults. Diabet Med 16, 853-860.

31. Frisancho AR (2007) Relative leg length as a biological marker to trace the developmental history of individuals and populations: growth delay and increased body fat. $\mathrm{Am} \mathrm{J}$ Hum Biol 19, 703-710.

32. Bogin N \& Beydoun B (2007) The relationship of sitting height ratio to body mass index and fatness in the United States, 1988-1994. Hum Ecol Spec Iss no. 15, 1-8.

33. Gunnell DJ, Smith GD, Frankel SJ et al. (1998) Socioeconomic and dietary influences on leg length and trunk length in childhood: a reanalysis of the Carnegie (Boyd Orr) survey of diet and health in prewar Britain (1937-39). Paediatr Perinat Epidemiol 12, Suppl. 1, 96-113.

34. Martin RM, Smith GD, Frankel S et al. (2004) Parents' growth in childhood and the birth weight of their offspring. Epidemiology 15, 308-316.

35. Harvard TH Chan School of Public Health (2017) Obesity Definition: Why Use BMI? http://www.hsph.harvard.edu/obe sity-prevention-source/obesity-definition/obesity-definition-fullstory/ (accessed December 2017).

36. Lev B \& Sunder S (1979) Methodological issues in the use of financial ratios. J Account Econ 1, 187-210.

37. World Health Organization (1995) Physical Status: The Use and Interpretation of Anthropometry. Report of a WHO Expert Committee. WHO Technical Report Series no. 854. Geneva: WHO.

38. Borruel S, Molto JF, Alpanes M et al. (2014) Surrogate markers of visceral adiposity in young adults: waist circumference and body mass index are more accurate than waist hip ratio, model of adipose distribution and visceral adiposity index. PLoS One $\mathbf{9}$, e114112.

39. Song X, Jousilahti P, Stehouwer CD et al. (2015) Cardiovascular and all-cause mortality in relation to various anthropometric measures of obesity in Europeans. Nutr Metab Cardiovasc Dis 25, 295-304.

40. Janssen I (2013) The public health burden of obesity in Canada. Can J Diabetes 37, 90-96.

41. Visscher TL, Rissanen A, Seidell JC et al. (2004) Obesity and unhealthy life-years in adult Finns: an empirical approach. Arch Intern Med 164, 1413-1420.

42. Ashwell M, Mayhew L, Richardson J et al. (2014) Waist-toheight ratio is more predictive of years of life lost than body mass index. PLoS One 9, e103483.

43. Hsieh SD, Yoshinaga H, Muto T et al. (2000) Health risks among Japanese men with moderate body mass index. Int $J$ Obes Relat Metab Disord 24, 358-362.

44. Hardy R, Wadsworth M \& Kuh D (2000) The influence of childhood weight and socioeconomic status on change in adult body mass index in a British national birth cohort. Int $J$ Obes Relat Metab Disord 24, 725-734.

45. Lindeboom M, Llena-Nozal A \& van der Klaauw B (2009) Parental education and child health: evidence from a schooling reform. J Health Econ 28, 109-131.

46. Fan W \& Yan Z (2010) Factors affecting response rates of the web survey: a systematic review. Comput Hum Behav 26, 132-139.

47. Tin Tin S, Woodward A \& Ameratunga S (2014) Estimating bias from loss to follow-up in a prospective cohort study of bicycle crash injuries. Inj Prev 20, 322-329.

48. Cardoso HF (2008) Secular changes in body height and weight of Portuguese boys over one century. Am J Hum Biol 20, 270-277.

49. Padez C (2007) Secular trend in Portugal. J Hum Ecol 22, $15-22$.

50. Asao K, Kao WH, Baptiste-Roberts K et al. (2006) Short stature and the risk of adiposity, insulin resistance, and type 2 diabetes in middle age: the Third National Health and Nutrition Examination Survey (NHANES III), 1988-1994. Diabetes Care 29, 1632-1637.

51. Florencio TT, Ferreira HS, Cavalcante JC et al. (2007) Short stature, abdominal obesity, insulin resistance and alterations in lipid profile in very low-income women living in Maceio, northeastern Brazil. Eur J Cardiovasc Prev Rehabil 14, 346-348.

52. Azevedo A, Ramos E, von Hafe P et al. (1999) Upper-body adiposity and risk of myocardial infarction. $J$ Cardiovasc Risk 6, 321-325. 